\title{
Identifikasi Sebaran Limbah Kelapa Sawit Di Desa Kuala Mandor A Menggunakan Metode Konduktivitas Elektromagnetik
}

\author{
Allishya Purrya, Muliadi ${ }^{*}$, Zulfian ${ }^{\mathrm{a}}$
}

\author{
aProdi Geofisika, FMIPA Universitas Tanjungpura, bProdi Ilmu Kelautan, FMIPA Universitas Tanjungpura \\ *Email : muliadi@fmipa.untan.ac.id
}

Abstrak

\begin{abstract}
Sebaran limbah kelapa sawit telah berhasil diidentifikasi menggunakan metode konduktivitas elektromagnetik. Metode ini menggunakan sistem konfigurasi vertical coplanar (VCP) dan sistem konfigurasi horizontal coplanar (HCP). Konfigurasi VCP memiliki penetrasi kedalaman 3 meter sedangkan konfigurasi HCP memiliki penetrasi kedalaman 6 meter. Tanah yang terkontaminasi limbah kelapa sawit memiliki nilai konduktivitas $110 \mathrm{mS} / \mathrm{m}$ hingga $210 \mathrm{mS} / \mathrm{m}$ pada kedalaman 3 meter, sedangkan pada kedalaman 6 meter bernilai $105 \mathrm{mS} / \mathrm{m}$ hingga $170 \mathrm{mS} / \mathrm{m}$. Sebaran limbah kelapa sawit ini teridentifikasi menyebar ke arah Timur, Tenggara, dan Barat Daya sejauh 25 meter hingga 65 meter dari kolam penampungan limbah kelapa sawit.
\end{abstract}

Kata Kunci : Limbah Kelapa Sawit, Metode Konduktivitas Elektromagnetik, Konduktivitas

\section{Latar Belakang}

Kelapa sawit merupakan komoditi yang sangat memberikan manfaat dan harapan untuk meningkatkan perekonomian negara dan daerah dari sektor non migas. Perkembangan bisnis budidaya tanaman kelapa sawit di Indonesia telah memberikan dampak yang sangat positif dalam pembangunan nasional. Salah satunya dikarenakan tanaman kelapa sawit merupakan penghasil devisa dari sektor nonmigas yang cukup penting, dan sebagai peningkatan pendapatan petani dan masyarakat [1].

Semakin banyaknya budidaya tanaman kelapa sawit di Indonesia yang sudah menjadi sumber pendapatan bagi petani, maka jumlah pabrik pengolahan kelapa sawit juga semakin bertambah. Dengan adanya pabrik pengolahan industri tersebut, maka akan menimbulkan dampak negatif yang diakibatkan oleh limbah hasil keluaran dari industri kelapa sawit. Industri pengolahan kelapa sawit menghasilkan limbah salah satunya adalah limbah cair. Limbah cair memiliki potensi yang paling besar sebagai pencemar lingkungan. Limbah yang ada di penampungan akan merembes ke dalam tanah melalui jalur rekahan tanah. Akibatnya akan mencemari sumur air bersih warga di sekitar pembuangan limbah. Maka dari itu kerugian yang ditimbulkan oleh pengolahan limbah cair yang kurang baik akan memberikan dampak negatif terhadap lingkungan berupa pencemaran lingkungan karena mengandung nilai COD (Chemical Oxygen Deman), BOD (Biologycal Oxygen Demand), serta padatan tersuspensi.

Untuk mengidentifikasi limbah yang mencemari tanah dapat dilakukan dengan menggunakan metode konduktivitas elektromagnetik. Sebelumnya Aswan,. dkk (2014) telah berhasil menggunakan metode konduktivitas elektromagnetik, untuk mengkaji arah sebaran dan letak akumulasi lindi yang dapat mencemari air tanah [2]. Sampurno, (2015) berhasil menggunakan metode konduktivitas elektromagnetik, untuk mengetahui posisi akuifer [3].

Desa Kuala Mandor A, merupakan desa yang memiliki kolam penampungan limbah kelapa sawit. Berdasarkan observasi lapangan, kolam tersebut berada dekat daerah aliran sungai dan permukiman. Oleh karena itu, diperlukan penyelidikan mengenai sebaran limbah kelapa sawit di desa tersebut. Metode yang digunakan pada penelitian ini adalah metode konduktivitas elektromagnetik. Metode ini dipilih karena bersifat nondestruktif dan eksplorasi dangkal. Penelitian ini berguna untuk mengetahui sebaran limbah kelapa sawit secara mapping.

\section{Metodologi \\ 2.1 Metode Elektromagnetik}

Survei elektromagnetik (EM) pada dasarnya diterapkan untuk mengetahui perambatan gelombang elektromagnetik, yang terbentuk akibat adanya arus bolak-balik dan medan magnet. Medan magnet primer dihasilkan oleh arus bolak-balik yang melawati sebuah kumparan yang terdiri dari lilitan kawat. Respon di bawah permukaan berupa medan magnet sekunder dan resultan medan, terdekteksi sebagai arus bolak-balik yang menginduksi arus listrik pada koil penerima (reciver) sebagai akibat adanya induksi medan megnetik.

Setelah mendapatkan perbedaan medan EM primer dan EM sekunder, dapat ditentukan konduktivitas dari mineral permukaan tanah, seperti persamaan (1) sebagai berikut [4] : 


$$
\sigma_{a}=\frac{4}{\omega \mu_{0} S^{2}}\left(\frac{H_{S}}{H_{P}}\right)
$$

Dimana :

$\sigma_{a}=$ Konduktivitas semu (Siemen $/ \mathrm{m}$ )

$H_{S}=$ Medan magnet sekunder $(\mathrm{A} / \mathrm{m})$

$H_{P}=$ Medan magnet primer $(\mathrm{A} / \mathrm{m})$

$\omega=2 \pi f f=$ Frekuensi gelombang $\operatorname{EM}(\mathrm{Hz})$

$\mu_{0}=$ Permeabilitas vakum $\left(4 \pi \times 10^{-7} \mathrm{H} / \mathrm{m}\right)$

$\mathrm{S}=$ Jarak pemancar dan penerima $(\mathrm{m})$

Metode EM memaparkan sinyal kontinu dengan frekuensi pasti. Perangkat CMD-4 dari GF Instrument, CMD-4 membangkitkan gelombang elektromagnetik sebagai konduktivitimeter dengan menggunakan frekuensi tetap sebesar 9,8 kHz dan jarak koil yang terpisah sejauh 3,66 meter. Perangkat ini dioperasikan dengan sumber tenaga 8 sel alkalin $C$ yang mampu bertahan selama 15 hingga 30 jam. Pada kedua ujung yang terpisah sejauh 3,66 meter terdapat sebuah transmitter dan receiver.

Penetrasi kedalaman untuk sistem konfigurasi Vertical Coplanar (VCP) dapat mencapai 3 meter dan untuk penetrasi kedalaman sistem konfigurasi Horizontal Coplanar (HCP) dapat mencapai kedalaman 6 meter. Dengan menggabungkan dua teknik tersebut akan didapatkan pengukuran konduktivitas lebih jelas sebagai fungsi instrument untuk kedua dipole vertikal dan horizontal [5].

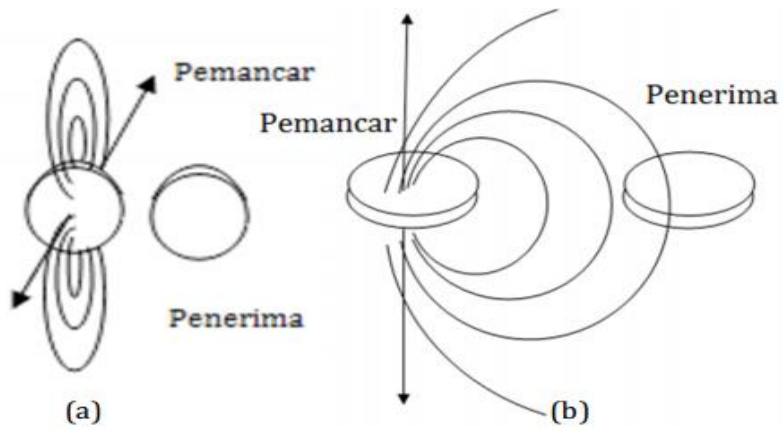

Gambar 1.

(a) Sistem konfigurasi vertikal coplanar (VCP)

(b) Sistem konfigurasi horizontal coplanar (HCP)

\subsection{Lokasi Penelitian}

Penelitian dilaksanakan di Desa Kuala Mandor A, Kecamatan Kuala Mandor B, Kabupaten Kubu Raya. Pengambilan data dilakukan dari tanggal 17 juli 2018 dan tanggal 7 agustus 2018. Lokasi penelitian berada pada koordinat 49M 337946,9 - 3379098,2 mE, 999771,7 - 9998221,4 mS. Peta lokasi penelitiannya dapat dilihat pada Gambar 2 .

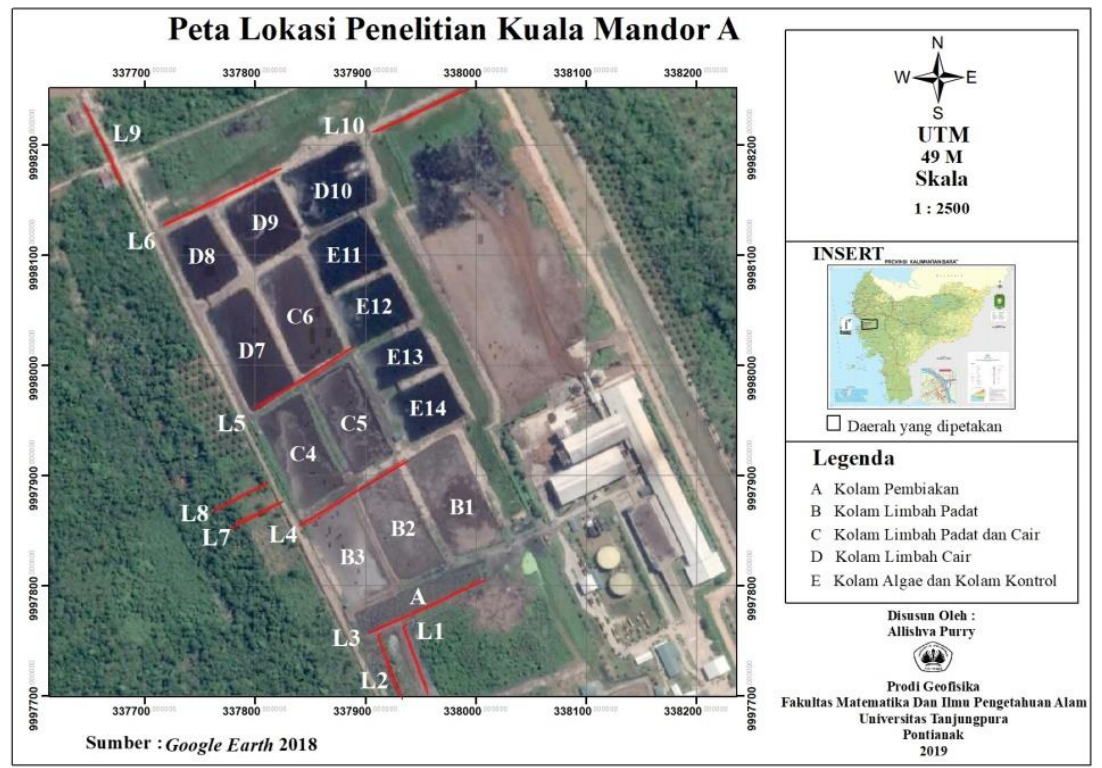

Gambar 2. Lokasi penelitian dan lintasan penelitian

\subsection{Akusisi Data}

Proses Akusisi data menggunakan peralatan antara lain GPS, meteran, dan Elektromagnetikconductivity meter. Penelitian identifikasi konduktivitas elektromagnetik dengan jumlah lintasan berjumlah 10 lintasan yang menyebar pada lokasi penelitian (Gambar 2).

Lintasan L1 memiliki panjang lintasan 50 meter yang berada di koordinat 49M 337968,9 337946,9 mE dan 999771,7 - $9997673.5 \mathrm{mS}$. Lintasan L2 memiliki panjang lintasan 50 meter yang berada di koordinat 49M 337964,8 - 
337942,9 mE dan 9997719.2 - 9997674,2 mS. Lintasan L3 memiliki panjang lintasan 100 meter yang berada di koordinat 49M 337957,7 337998,08 mE dan 9997794,5 - 9997749,6 mS. Lintasan L4 memiliki panjang lintasan 100 meter yang berada di koordinat 49M 337925,6 337841,5 mE dan 9997883,2 - 9997862,08 mS. Lintasan L5 memiliki panjang lintasan 100 meter yang berada di koordinat 49M 337792,9 337877,3 mE dan 999797,5 - 9997952,9 mS. Lintasan L6 memiliki panjang lintasan 100 meter yang berada di koordinat 49M 337798,8 $337711,9 \mathrm{mE}$ dan 9998119,1 - 9998166,1 mS. Lintasan L7 memiliki panjang lintasan 42 meter yang berada di koordinat 49M 337783,6 $337819,8 \mathrm{mE}$ dan 997862,08 - 9997878,3 mS. Lintasan L8 memiliki panjang 42 meter yang berada di koordinat 49M 337786,7 - 337818,3 $\mathrm{mE}$ 9997886,9 - 9997870,3 mS. Lintasan L9 memiliki panjang lintasan 50 meter yang berada di koordinat 49M 337657,8 - 337680,7 $\mathrm{mE}$ dan 9998215,2 - 9998173,3 mS Lintasan L10 memiliki panjang lintasan 100 meter yang berada di koordinat 49M 337993,9 - 337909,8 $\mathrm{mE}$ dan 9998221,4 - 9998271,79 mS. Lintasan yang diambil berada pada daerah kolam penampungan di area perkebunan dan dekat permukiman. Hal ini dilakukan agar lintasan tersebut mewakili daerah yang diduga terkontaminasi limbah kelapa sawit.

\subsection{Diagram Alir}

Pelaksanaan penelitian ini dilakukan melalui beberapa tahap, yaitu tahap pengolahan data dan interpretasi data. Adapun tahap-tahap penelitian tersebut disajikan dalam bentuk diagram alir seperti pada Gambar 3.

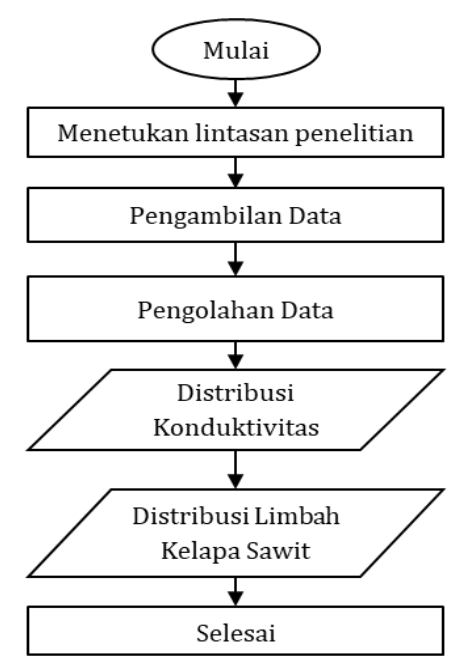

Gambar 3. Diagram alir penelitian

\section{Hasil dan Pembahasan}

Penelitian ini bertujuan untuk mengetahui sebaran limbah kelapa sawit di daerah Kuala Mandor A, Kabupaten Kubu Raya. Untuk mengidentifikasi limbah tersebut digunakan metode konduktivitas elektromagnetik, yaitu konfigurasi VCP dan HCP. Selanjutnya dari hasil akan diperoleh distribusi konduktivitas limbah kelapa sawit.

Secara geologi daerah penelitian memiliki jenis tanah aluvial. Nilai konduktivitas tanah aluvial berkisar kurang dari $100 \mathrm{mS} / \mathrm{m}$ [6]. Sehingga nilai konduktivitas ini yang menjadi acuan dalam interpretasi tanah aluvial yang tercemar maupun yang tidak tercemar oleh limbah kelapa sawit.

\subsection{Distribusi Konduktivias Menggunakan Konfigurasi VCP}

Konfigurasi VCP memiliki kedalaman 3 meter pada posisi perangkat tepat berada di permukaan tanah. Udara di atas permukaan tanah tidak berpengaruh besar terhadap nilai konduktivitas yang terukur di bawah permukaan tanah. Penetrasi medan magnet akan langsung menuju ke bawah permukaan tanah pada kedalaman 3 meter. Pada Gambar 4 dapat dilihat distribusi nilai konduktivitas tanah berkisar antra $20 \mathrm{mS} / \mathrm{m}$ hingga $210 \mathrm{mS} / \mathrm{m}$ yang ditunjukan dengan warna ungu muda sampai merah. Berdasarkan hasil analisis data yang disesuaikan dengan hasil referensi konduktivitas batuan, konduktivitas limbah, mineral terutama air dan kondisi geologi, maka diperoleh nilai konduktivitas limbah kelapa sawit secara mapping.

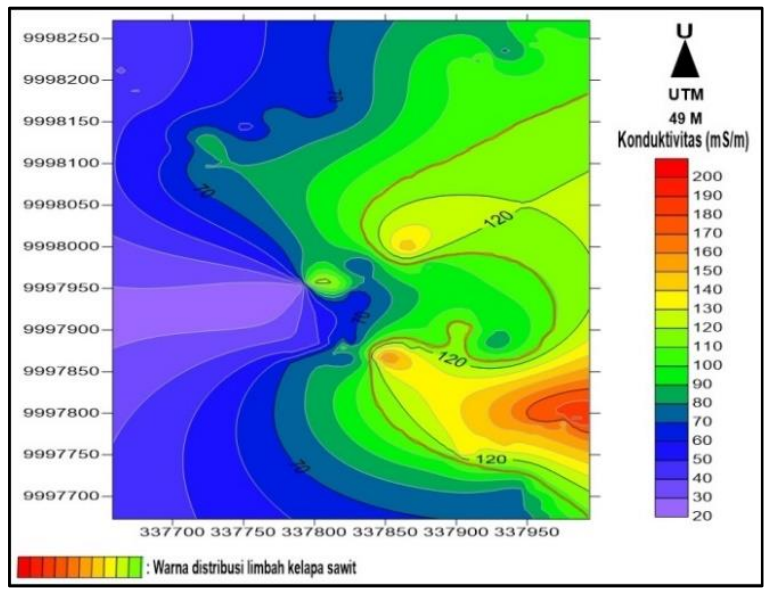

Gambar 4. Distribusi Konduktivitas berdasarkan konfigurasi VCP

Pola distribusi konduktivitas limbah kelapa sawit dapat dilihat pada Gambar 4. Berdasarkan gambar tersebut terlihat bahwa distribusi konduktivitas yang terkontaminasi limbah 
kelapa sawit berkisar dari $110 \mathrm{mS} / \mathrm{m}$ hingga 210 $\mathrm{mS} / \mathrm{m}$, yang ditunjukan oleh warna hijau muda sampai jingga. Kemudian nilai konduktivitas yang tidak terkontaminasi limbah kelapa sawit ditunjukkan oleh warna ungu muda sampai hijau tua, dengan nilai konduktivitas sebesar $20 \mathrm{mS} / \mathrm{m}$ hingga $100 \mathrm{mS} / \mathrm{m}$.

Pada Gambar 5 dapat dilihat overlay distribusi nilai konduktivitas pada google earth di lokasi penelitian. Zona yang tercemar limbah kelapa sawit berada pada kolam pendingin, kolam pengasaman, kolam pembiakan dan kolam anaerobik primer, yang ditunjukkan oleh garis putus-putus berwarna merah, biru, hijau dan hitam. Dengan konduktivitas sebesar $110 \mathrm{mS} / \mathrm{m}$ hingga $210 \mathrm{mS} / \mathrm{m}$ yang ditunjukan oleh warna hijau muda sampai jingga. Kolam ini memiliki kandungan minyak dan lemak yang tinggi dari limbah kelapa sawit [7]. Selain itu juga limbah kelapa sawit memiliki kandungan logam seperti ( $\mathrm{Fe}, \mathrm{Cu}, \mathrm{Na}, \mathrm{H}_{2} \mathrm{~S}$ ) [8]. Kandungan logam inilah yang meyebabkan limbah kelapa sawit memiliki sifat elektrolit yang tinggi sehingga limbah kelapa sawit lebih konduktif [9].

Gambar 5. Overlay distribusi konduktivitas

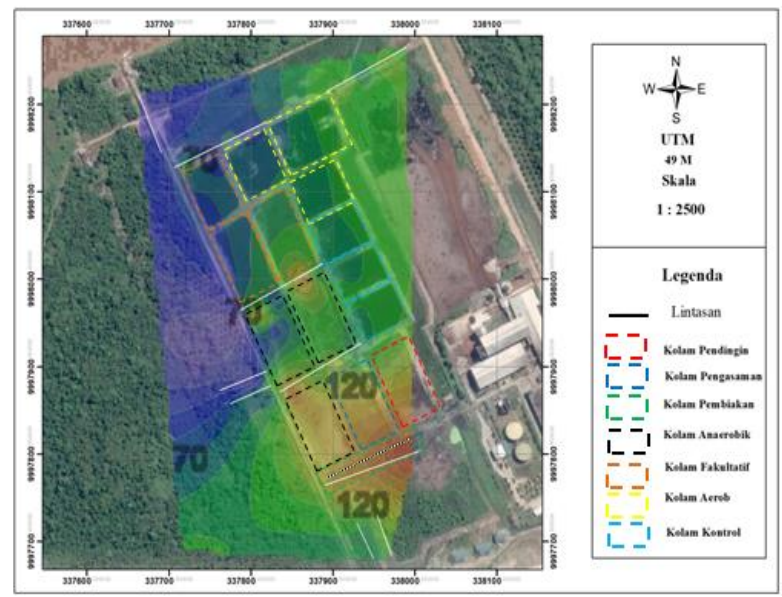

Kedalam Google Earth pada lokasi penelitian

Sedangkan untuk zona yang tidak terkontaminasi limbah kelapa sawit berada pada kolam fakultatif dan kolam aerob, yang ditunjukan oleh garis putus-putus berwarna jingga dan kuning. Dengan konduktivitas sebesar $20 \mathrm{mS} / \mathrm{m}$ hingga $100 \mathrm{mS} / \mathrm{m}$ yang ditunjukkan oleh warna ungu muda sampai hijau tua. Dimana kolam ini berfungsi untuk menurunkan kadar minyak dan lemak dari limbah kelapa sawit [7]. Kadar limbah yang ada pada kolam-kolam ini sudah tidak konduktif lagi karena bobot limbah yang ada di kolam sudah berkurang.

Distribusi konduktivitas limbah kelapa sawit menyebar dari arah Timur ke Tenggara. Limbah kelapa sawit merembes sejauh 55 meter ke arah Tenggara dari kolam pembiakan (kolam A).
Limbah kelapa sawit merembes sejauh 25 meter ke arah Barat Daya dari kolam pembiakan (kolam A), dan merembes sejauh 110 meter ke arah Timur Laut dari kolam aerob.

\subsection{Distribusi Konduktivitas Menggunakan Konfigurasi HCP}

Konfigurasi HCP memiliki kedalaman 6 meter. Udara di atas permukaan tanah tidak berpengaruh besar terhadap nilai konduktivitas yang terukur di bawah permukaan tanah. Gambar 6 memperlihatkan lapisan tanah yang terkontaminasi dan yang tidak terkontaminasi limbah kelapa sawit. Secara geologi daerah ini memiliki jenis tanah aluvial. Tanah aluvial memiliki nilai konduktivitas kurang dari 100 $m S / m$. Pada lapisan ini, tanah aluvial memiliki nilai konduktivitas $25 \mathrm{mS} / \mathrm{m}$ hingga $105 \mathrm{mS} / \mathrm{m}$ yang ditunjukkan oleh warna ungu muda sampai hijau muda. Zona yang memiliki nilai tersebut diduga merupakan tanah aluvial yang tidak tercemar limbah kelapa sawit.

Sedangkan zona yang tercemar limbah kelapa sawit memiliki konduktivitas lebih tinggi dari aluvial. Hal ini disebabkan karena sifat elektrolit yang tinggi dari limbah kelapa sawit yang mengandung minyak dan lemak mengakibatkan limbah kelapa sawit lebih konduktif. Zona yang tercemar limbah kelapa sawit ini memiliki nilai konduktivitas sebesar $105 \mathrm{mS} / \mathrm{m}$ hingga $170 \mathrm{mS} / \mathrm{m}$ yang ditunjukan oleh warna hijau muda sampai jingga.

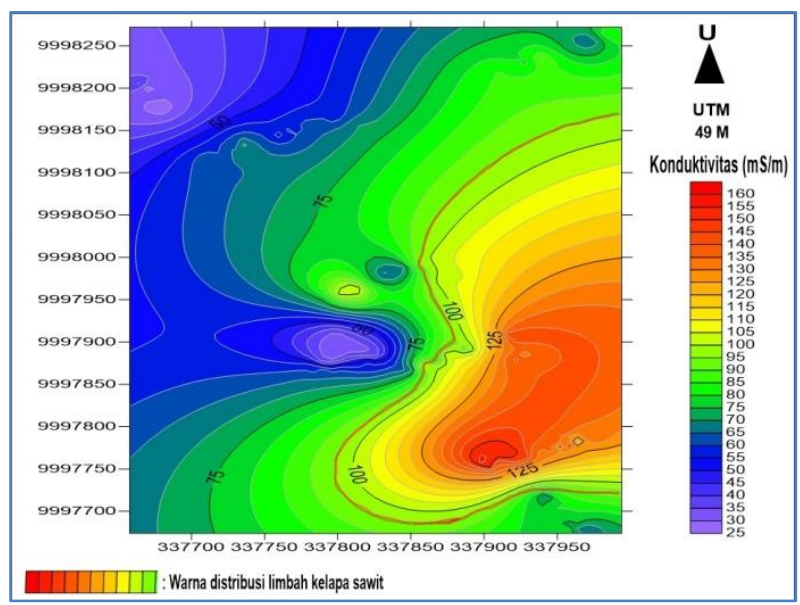

Gambar 6. Distribusi Konduktivitas berdasarkan konfigurasi HCP

Zona yang tidak tercemar limbah kelapa sawit berada pada kolam (C6 - D11), yang berfungsi untuk mengurangi kadar BOD, COD, minyak lemak, dan logam ( $\mathrm{Fe}, \mathrm{Cu}, \mathrm{Na}, \mathrm{H}_{2} \mathrm{~S}$ ). Sehinga daya hantar listrik pada tanah menjadi berkurang karena tidak tercemar limbah kelapa sawit. Konduktivitas yang terbaca menjadi lebih rendah. Sedangkan zona yang terkontaminasi 
limbah kelapa sawit memiliki kandungan limbah berupa lemak hasil pengolahan sawit yang langsung dialirkan ke kolam-kolam (A - C5). Kolam-kolam tersebut terdapat kandungan organik seperti BOD, COD, oksigen terlarut, minyak lemak, dan lain-lain. Selain itu juga terdapat zat anorganik seperti $\mathrm{pH}$, alkalinitas, logam ( $\mathrm{Fe}, \mathrm{Cu}, \mathrm{Na}, \mathrm{H}_{2} \mathrm{~S}$ ) [10]. Kandungan inilah yang menyebabkan limbah kelapa sawit mempunyai sifat elektrolit yang tinggi, sehingga limbah kelapa sawit lebih konduktif [9]

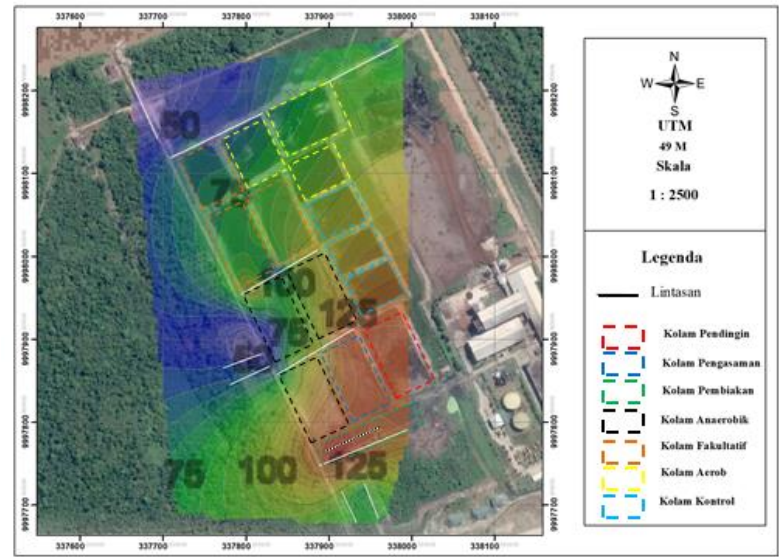

Gambar 7. Overlay Distribusi Konduktivitas kedalam Google Earth pada lokasi penelitian

Gambar 7 memperlihatkan distribusi konduktivitas limbah kelapa sawit kaitannya dengan kolam-kolam penampungan pada lokasi penelitian. Penyebaran limbah kelapa sawit dapat juga dilihat dengan overlay hasil sebaran ke google earth. Zona yang tidak terkontaminasi limbah kelapa sawit secara umum berada pada kolam fakultatif dan kolam aerob yang ditunjukan oleh garis putus-putus berwarna jingga dan kuning. Kedua kolam ini berfungsi untuk mengurangi kandungan minyak dan lemak dari limbah kelapa sawit [7]. Sehingga limbah yang berada pada kedua kolam ini sudah tidak terlalu konduktif lagi.

Distribusi konduktivitas yang tercemar limbah kelapa sawit bernilai $105 \mathrm{mS} / \mathrm{m}$ hingga $170 \mathrm{mS} / \mathrm{m}$ berada pada kolam pendingin, kolam pengasaman, kolam pembiakan, dan kolam anaerobik primer, yang ditunjukan garis putusputus berwarna merah, biru, hijau dan hitam. Hal ini disebabkan keempat kolam ini memiliki kadar minyak dan lemak yang masih tinggi [9]. Limbah kelapa sawit juga memiliki kandungan logam [8]. Limbah kelapa sawit ini menyebar hingga kedalaman 6 meter. Penyebaran limbah pada kedalaman 6 meter diduga tanah pada zona ini memiliki jalur rembesan yang mengakibatkan kondisi bawah permukaan tanah dapat meloloskan fluida (limbah kelapa sawit).

Pola distribusi konduktivitas limbah kelapa sawit pada Gambar 7 menunjukan konduktivitas tinggi yang menyebar dari arah Timur ke Tenggara. Limbah kelapa sawit merembes sejauh 65 meter ke arah Tenggara dari kolam pembiakan (kolam A), dan merembes sejauh 55 meter ke arah Timur dari kolam penampungan (kolam kontrol). Kemudian 60 meter merembes ke arah Barat Daya dari kolam pembiakan (kolam A).
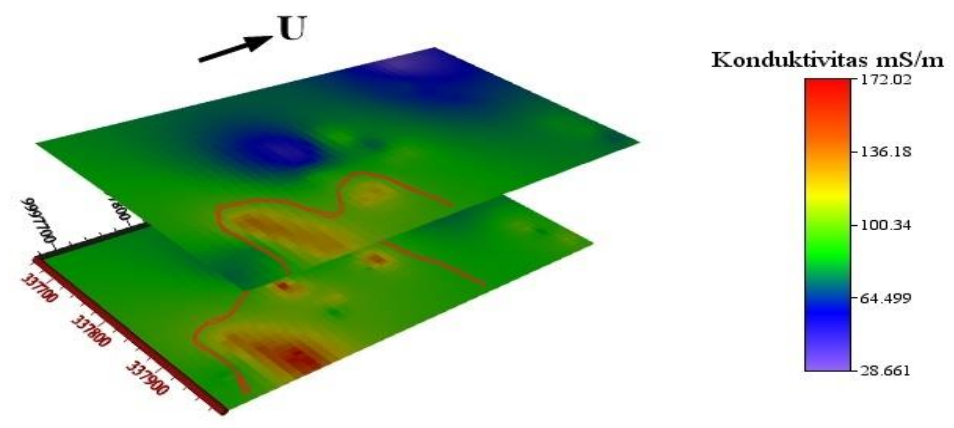

Gambar 8. Sebaran limbah kelapa sawit kedalaman 3 meter hingga 6 meter 


\subsection{Sebaran Limbah Kelapa Sawit}

Pada Gambar 8 dapat dilihat pola distribusi gabungan konfigurasi VCP dan konfigurasi HCP. Gambar ini juga menjelaskan distribusi konduktivitas limbah kelapa sawit menyebar dari kedalaman 3 meter sampai kedalaman 6 meter. Seiring dengan pertambahan kedalaman hingga 6 meter terlihat bahwa limbah kelapa sawit menyebar dari arah Timur ke Tenggara dari kolam penampungan limbah. Hal ini diperlihatkan dengan nilai konduktivitas yang lebih tinggi dari arah Timur dan Tenggara dari kedalaman 3 meter hingga 6 meter. Dikarenakan pada wilayah Timur merupakan posisi kolam pendingin, dimana limbah yang baru di keluarkan dari pabrik langsung dialirkan ke kolam tersebut yang mengalir ke Tenggara.

Distribusi konduktivitas limbah kelapa sawit menyebar dari arah Timur ke Tenggara. Pada kedalaman 3 meter limbah kelapa sawit merembes sejauh 55 meter arah Tenggara dari kolam pembiakan (kolam A), dan merembes sejauh 25 meter ke arah Barat Daya dari kolam pembiakan (kolam A). Pada arah Timur Laut limbah kelapa sawit merembes sejauh 110 meter dari kolam aerob. Sedangkan pada kedalaman 6 meter limbah kelapa sawit merembes sejauh 65 meter ke arah Tenggara dari kolam penampungan (kolam A). Pada arah Timur limbah kelapa sawit merembes sejauh 55 meter dari kolam penampungan (kolam kontrol). Kemudian 60 meter merembes ke arah barat daya dari kolam pembiakan (kolam A).

Penyebaran limbah kelapa sawit ke arah Tenggara pada kedalaman 3 meter dan kedalaman 6 meter dikarenakan pada zona ini mengikuti aliran topografi kerena di wilayah Tenggara topografinya lebih rendah dari penampungan. Sehingga limbah yang ada di penampungan akan mengikuti lapisan bawah pemukaan, menyebar pada daerah yang lebih rendah dan mengumpul pada daerah terendah. Sedangkan penyebaran limbah kelapa sawit ke arah Timur untuk kedalaman 3 meter dan 6 meter, dengan keadaan di lokasi pada zona ini terdapat penumpukan tandan kosong yang baru dikeluarkan dari pabrik. Penyebaran limbah ke arah Timur dan Tenggara diduga dikarenakan adanya jalur rembesan lapisan tanah. Hal tersebut menyebabkan limbah kelapa sawit dapat mengalir dan terakumulasi pada zona yang memiliki permeabilitas tinggi.

Rembesan limbah kelapa sawit ke dalam tanah juga disebabkan mengikuti zona rekahan tanah. Struktur lapisan tanah yang memiliki jalur rembesan memungkinkan bagi tanah tercemar limbah kelapa sawit. Pada kedalaman 6 meter diduga memiliki jalur rembesan yang lebih besar dari kedalaman 3 meter. Sehingga penyebaran limbah kelapa sawit dari kedalaman 3 meter hingga 6 meter menyebar ke arah Timur, Tenggara, dan Barat Daya dari kolam pendingin, pengasaman, pembiakan, dan anaerob primer, menembus ke lapisan dalam. Distribusi konduktivitas limbah kelapa sawit di kedalaman 3 meter lebih kecil penyebarannya dibandingkan dengan kedalaman 6 meter. Penyebaran konduktivitas limbah kelapa sawit semakin meluas dengan bertambahnya kedalamaan tanah.

\section{Penutup \\ 4.1 Kesimpulan}

Berdasarkan hasil penelitian dapat disimpulkan bahwa tanah yang terkontaminasi limbah kelapa sawit di Desa Kuala Mandor A memiliki nilai konduktivitas berkisar $110 \mathrm{mS} / \mathrm{m}$ - $210 \mathrm{mS} / \mathrm{m}$, untuk kedalaman 3 meter. Sedangan untuk kedalaman 6 meter tanah yang terkontaminasi limbah kelapa sawit memiliki nilai konduktivitas berkisar $105 \mathrm{mS} / \mathrm{m}-170$ $\mathrm{mS} / \mathrm{m}$.

Dari hasil tersebut dapat diketahui sebaran konduktivitas limbah kelapa sawit untuk konfigurasi VCP, menyebar ke arah Timur Laut sejauh 110 meter, menyebar sejauh 55 meter ke arah Tenggara, dan 25 meter menyebar ke arah Barat Daya dari kolam penampungan limbah kelapa sawit. Kemudian untuk konfigurasi HCP, limbah kelapa sawit menyebar ke arah Timur sejauh 55 meter, menyebar sejauh 65 meter ke arah Tenggara, dan 52 meter menyebar ke arah Barat Daya dari kolam penampungan limbah kelapa sawit.

\subsection{Saran}

Saran dari penelitian ini perlu melakukan pengukuran nilai konduktivitas tanah untuk mengetahui skala laboraturium nilai konduktivitas tanah yang tercemar maupun yang tidak tercemar limbah kelapa sawit.

\section{Daftar Pustaka}

[1] Pardamean, M., 2014. Mengelola Kebun dan Pabrik Kelapa Sawit Secara Profesional. PenebarSwadaya. Jakarta.

[2] Aswan, M., Sampurno, J., dan Satria putra, Y., 2014, Studi Rembesan Polutan Sampah Berdasarkan Metode Konduktivitas Elektromagnetik di Sekitar Tempat Pembuangan Akhir (TPA) Batulayang Kota Pontianak, Jurnal Prisma Fisika FMIPA Universitas Tanjungpura, Pontianak.

[3] Sampurno, J. 2015. Aplilasi Metode Elektromagnetik untuk Identifikasi Akuifer di Taman Universitas Tanjungpura. 
[4] Reynolds, J.M.,1997. An Introduction to Applied and Environmental Geophysics. England ; John Wiley \& Sons Ltd.

[5] Dohr, 1981. Applied Geophysics. Halsted Press, New York.

[6] Loke, 2015. Tutorial. 2-D and 3-D Electrical Imaging Surveys. Malaysia

[7] Wibisono., 2013. Pengolahan Limbah Cair Pabrik Kelapa Sawit POME (Palm 0il Mail Effluent).

[8] Apriani., 2011. Pemanfaatan Limbah Cair Kelapa Sawit Sebagai Energi Artanatif terbarukan (biogas). Tesis. Program studi Pengolahan Sumber Daya Alam dan Lingkungan, Institusi Pertanian Bogor, Bogor.

[9] Vogelsang., 1995,. Environmental Geopysics Practical Guide, Springer.

[10] Sihaloho,. 2008. Analisis Kandungan Anomia dari Limbah Cair Inlet dan Oulet dari beberapa Industri Kelapa Sawit. Karya Ilmial. Medan Sumatra

Utara 